\title{
KEPATUHAN PENGGUNAAN ALAT PELINDUNG DIRI (APD) DI LABORATORIUM PADA MAHASISWA PRODI DIPLOMA ANALIS KESEHATAN UNIVERSITAS MH THAMRIN
}

\author{
Catu Umirestu Nurdiani ${ }^{1)}$, Tri Krianto ${ }^{2)}$ \\ Fakultas Kesehatan Masyarakat Universitas Indonesia \\ ctani_enan@yahoo.com
}

\begin{abstract}
ABSTRAK
Setiap pekerjaan memiliki risiko atau berpotensi mengalami kecelakaan kerja. Beberapa penyebab kecelakaan di laboratorium dapat bersumber dari sikap dan tingkah laku para pekerja, keadaan ang tida aman dan kurangnya pengawasan. Penelitian ini bertujuan untuk mengetahui kepatuhan dan faktor terkait penggunaan Alat Pelindung Diri (APD) di laboratorium pada mahasiswa Prodi Diploma Analis Kesehatan Universitas MH Thamrin. Studi penelitian ini bersifat deskriptif analitik dengan desain cross sectional. Sampel sebanyak 328 responden dengan variabel dependen adalah kepatuhan penggunaan APD dan variabel indepennya adalah faktor predisposisi (pengetahuan, sikap), faktor pemungkin (ketersediaan adanya APD, kenyamanan APD), faktor penguat (rekan mahasiswa, pengawasan, peraturan, sanksi). Analisis dilakukan dengan regresi logistic. Responden yang patuh menggunakan APD sebanyak 227 (69,2\%) dan yang tidak patuh menggunakan APD sebanyak 101 (30,8\%). Variabel yang berhubungan signifikan dengan kepatuhan penggunaan APD adalah pengetahuan $(\mathrm{OR}=1,733)$, ketersediaan $(\mathrm{OR}=0,639)$, rekan mahasiswa $(\mathrm{OR}=3,039)$, dan peraturan $(\mathrm{OR}=0,274)$. Variabel paling dominan yang berhubungan dengan kepatuhan penggunaan APD adalah rekan mahasiswa dengan $\mathrm{OR}=3,039$ yang artinya mahasiswa yang komunikasinya dengan mahasiswa lainnya baik berpeluang 3,039 lebih tinggi daripada mahasiswa yang komunikasinya dengan mahasiswa lain tidak baik. Untuk penelitian selanjutnya agar ditambahkan dengan teknik kualitatif.
\end{abstract}

Kata kunci: Kecelakaan, Kepatuhan, APD, rekan mahasiswa

\section{PENDAHULUAN}

Setiap pekerjaan memiliki risiko atau berpotensi mengalami kecelakaan kerja. Kecelakaan kerja akan merugikan berbagai pihak dari segi ekonomi Negara, kerugian yang diterima oleh pekerja sehingga akan meningkatkan angka ketergantungan (Kementerian Kesehatan Republik Indonesia, 2015). Keikutsertaan Indonesia menjadi anggota ASEAN Free Trade Association (AFTA) yang sudah berlaku mulai dari 2010 dan North Atlantic Free Trade Association (NAFTA) berlaku paling lambat tahun 2020, tenaga kesehatan dituntut agar memiliki pengetahuan, keterampilan dan sikap yang memadai dan terus meningkatkan kualitasnya agar dapat bersaing dan sejajar dengan tenaga kesehatan dari mancanegara. (Universitas MH Thamrin, 2015).

Analis Kesehatan atau sering dikenal juga sebagai ahli teknologi laboratorium medik adalah tenaga profesi yang memegang peranan penting dalam analisa laboratorium kesehatan. Sarana laboratorium kesehatan merupakan institusi dengan jumlah petugas laboratorium yang cukup besar. Kegiatan di laboratorium kesehatan mempunyai risiko untuk terjadinya kecelakaan dan penyakit akibat kerja yang berasal dari factor fisik, kimia, ergonomik dan psikososial. (PMK Perdhaki,2000).

Pekerja laboratorium diharapkan terus meningkatkan pengetahuannya tentang sifat-sifat bahan dan teknik percobaan serta pengoperasian peralatan sebagaimana seharusnya. Kemampuan untuk mengendalikan bahaya kecelakaan di laboratorium memungkinkan para pekerja dapat menciptakan sendiri suasana yang aman dan nyaman dalam bekerja sehingga dapat bekerja dan berkarya secara maksimal. Beberapa penyebab kecelakaan di laboratorium dapat bersumber dari sikap dan tingkah laku para pekerja, keadaan yang tidak 
aman dan kurangnya pengawasan dari pangawas (Hartati, 2006).

Prodi Diploma Analis Kesehatan mendidik mahasiswa yang nantinya setelah lulus berprofesi sebagai analis kesehatan sesuai dengan kurikulum dan standar kompetensi, dengan praktikum sebesar 55\% dibandingkan teori sebesar 45\%. Prodi analis kesehatan mempunyai keunggulan dibidang mikrobiologi sehingga mahasiswa lebih sering praktikum menggunakan laboratorium mikrobiologi. Penggunaan laboratorium mikrobiologi digunakan mulai semester kedua hingga ujian akhir program bahkan sampai dunia pekerjaan. Semester kedua merupakan awal mahasiswa analis kesehatan menggunakan APD lengkap (masker, jas laboratorium, sarung tangan). Observasi yang dilakukan pada pertengahan semester dua mahasiswa analis kesehatan ada yang sakit types dan diare, hal ini membuat saya ingin meneliti kepatuhan APD pada mahasiswa yang selama ini belum pernah di teliti di Universitas MH Thamrin. Penelitian yang sejenis dilakukan oleh Yane (2007) dengan judul hubungan tingkat pengetahuan dan sikap dengan perilaku penggunaan alat pelindung diri pada mahasiswa Prodi DIII Analis kesehatan STIKes BTH Tasikmalaya. Hasil penelitian menunjukkan tidak terdapat hubungan antara tingkat pengetahuan dengan perilaku penggunaan APD $(\mathrm{p}=0,289$, alpha=0,05). Terhadap hubungan signifikan antara sikap dengan perilaku penggunaan APD ( $\mathrm{p}=0,004$, alpha=0,05). Tingkat pengetahuan tentang APD tidak mempengaruhi perilaku penggunaan APD namun sikap dapat mempengaruhi perilaku penggunaan APD pada mahasiswa.

Berdasarkan latar belakang di atas, maka rumusan masalah penelitian ini adalah kepatuhan penggunaan APD di laboratorium pada mahasiswa analis kesehatan belum mencapai $100 \%$ dan belum diketahuinya faktor-faktor yang berhubungan dengan kepatuhan penggunaan APD di laboratorium pada mahasiswa Prodi Diploma Analis KesehatanUniversitas MH Thamrin.

\section{BAHAN DAN METODE}

Studi penelitian yang digunakan bersifat deskriptif analitik dengan desain penelitian cross sectional. Desain studi cross sectional merupakan rancangan studi yang mempelajari hubungan antara variabel independen dan dependen yang dilihat dalam waktu yang bersamaan. Variabel dependen pada penelitian ini adalah kepatuhan penggunaan APD sedangkan variabel independennya adalah factor predisposisi (pengetahuan, sikap), factor pemungkin (ketersediaan APD, kenyamanan APD) factor penguat (rekan mahasiswa, pengawasan, peraturan, sanksi).

Populasi dalam penelitian ini adalah mahasiswa semester 2 dan semester 4 sebanyak 445. Sampel yang dipakai untuk penelitian berdasarkan kriteria inklusi dan eksklusi sebanyak 328 di Prodi Diploma Analis Kesehatan Universitas MH Thamrin pada bulan Mei 2019.

\section{HASIL}

Hasil penelitian terhadap mahasiswa Prodi Diploma Analis Kesehatan Universitas MH Thamrin didapatkan bahwa responden yang menjawab pertanyaan Penggunaan APD merupakan salah satu upaya perlindungan dari semua potensi yang dapat menimbulkan bahaya bagi analis kesehatan di laboratorium agar selalu dalam keadaan selamat dan sehat serta aman dan efisien (100\%). Kecelakaan kerja akibat tidak menggunakan APD merupakan kejadian yang tidak terduga dan tidak diharapkan, dikatakan tidak terduga 
karena dibelakang peristiwa tersebut tidak ada unsur kesengajaan dan selalu diikuti oleh kerugian material serta tidak diharapkan $(85,1 \%)$. Analis kesehatan merupakan profesi yang memiliki risiko bahaya kecelakaan dan terjadinya paparan penyakit ketika praktikum maka perlu penggunaan APD untuk meminimalisir risiko tersebut (100\%). Penggunaan APD bertujuan untuk melindungi mahasiswa agar tetap selamat dan sehat dalam praktikum (99,7\%). Penggunaan APD pada analis kesehatan tidak dapat meminimalisir angka kecelakaan kerja dan angka kesakitan (23,5\%). Penggunaan APD dianalis kesehatan bukan merupakan hak dasar perlindungan(13,1\%). Penggunaan APD berfungsi untuk melindungi analis kesehatan dari gangguan kesehatan yang mungkin terjadi sewaktu praktikum (96,0\%). Semua yang dapat membahayakan jiwa dan kesehatan, tidak termasuk dalam bahaya penggunaan APD (39\%). Perilaku kepatuhan menggunakan APD merupakan semua kegiatan manusia yang disadari dengan keselamatan dan kesehatan, namun tidak dapat diamati atau dilihat oleh pihak luar (74,7\%). Sarung tangan dapat melindungi mahasiswa dari bahan infeksius, mikroorganisme pada tangan mahasiswa $(99,4 \%)$. Salah satu manfaat dari APD adalah untuk mencegah terjadinya infeksi nosokomial (98,5\%). Hasil menunjukan erdasarkan tingkat pengetahuan responden dalam penelitian didapatkan responden yang memiliki pengetahuan baik $(75,6 \%)$ dan responden yang memiliki pengetahuan kurang $(24,4 \%)$.

Responden yang bersikap positif mendukung keselamatan dan kesehatan kerja (K3) dengan penggunaan APD di laboratorium yang sangat setuju $(94,2 \%)$ dan setuju $(5,8 \%)$. Sebelum melaksanakan praktikum, mempelajari dengan baik potensi bahaya yang ada pada saat saya praktikum yang sangat setuju $(71,3 \%)$ dan setuju (28,4\%) . Tidak mengikuti penggunaan APD di laboratorium tidak setuju $(64,0 \%)$ dan sangat tidak setuju $(33,2 \%)$. APD bukan merupakan prioritas utama dalam praktikum agar tercapai kondisi praktikum yang aman dan sehat yang tidak setuju $(62,2 \%)$ dan sangat tidak setuju $(23,2 \%)$. Rekan praktek yang tidak menggunakan APD sewaktu praktikum perlu ditegur dan diingatkan yang sangat setuju (72,9\%) dan setuju (25,0\%). Tidak ikut bertanggungjawab atas penggunaan APD yang tidak setuju $(71,3 \%)$ dan sangat tidak setuju (15,9\%). Ikut menjaga kebersihan dan kerapihan APD agar selalu dalam kondisi baik demi terciptanya lingkungan praktikum yang minim dari risiko bahaya yang sangat setuju $(76,8 \%)$ dan setuju (22,6\%). Kecelakaan akibat tidak menggunakan APD yang terjadi di laboratorium tidak perlu untuk dilaporkan yang tidak setuju $(68,0 \%)$ dan sangat tidak setuju $(27,7 \%)$. Tertarik untuk menggunakan APD yang sesuai dengan praktikum yang saya lakukan yang sangat setuju $(63,7 \%)$ dan setuju $(32,6 \%)$. Tidak peduli terhadap penggunaan APD di laboratorium yang tidak setuju $(62,8 \%)$ dan sangat tidak setuju $(33,2 \%)$. Hasil menunjukan berdasarkan Sikap penggunaan APD di Laboratorium pada mahasiswa Prodi diploma Analis Kesehatan Universitas MH Thamrin Tahun 2019 menunjukan bahwa responden yang berpartisipasi dalam penelitian memiliki sikap baik $(58,8 \%)$ dan responden yang memiliki sikap kurang (41,2\%).

Berdasarkan Pernyataan Kenyamanan penggunaan APD di Laboratorium pada mahasiswa Prodi diploma Analis Kesehatan Universitas MH Thamrin Tahun 2019 responden yang selama praktikum merasa nyaman menggunakan masker sebanyak $(95,1 \%)$, selama praktikum merasa nyaman menggunakan jas laboratorium $(99,4 \%)$, selama praktikum merasa nyaman menggunakan sarung tangan $(97,9 \%)$ dan yang merasa APD tersebut mengganggu aktivitas selama praktikum sebanyak (3,7\%). Hasil menunjukan bahwa responden 
yang merasa nyaman menggunakan APD $(3,7 \%)$ dan responden yang tidak nyaman menggunakan APD $(96,3 \%)$.

Hasil penelitian responden yang menyatakan rekan mahasiswa menggunakan APD secara lengkap (masker, jas laboratorium, sarung tangan) sebanyak (96,0\%), yang menyatakan rekan mahasiswa mengingatkan untuk menggunakan APD sebanyak (97,0\%) dan yang menyatakan rekan mahasiswa memotivasi untuk selalu menggunakan APD secara lengkap sebanyak (93,9\%). Hasil menunjukan bahwa responden yang berpartisipasi dalam penelitian merasa ada rekan mahasiswa sebanyak $(96,0 \%)$ dan tidak ada rekan mahasiswa $(4,0 \%)$.

Pada variabel pengetahuan didapat sebesar $72,2 \%$ responden dengan penetahuan baik patuh penggunaan APD, sedangkan pada responden pengetahuan kurang didapatkan sebesar 60,0\% patuh penggunaan APD. Hasil uji chi-square pengetahuan dengan kepatuhan penggunaan APD. Hasil uji chi-square pengetahuan dengan kepatuhan penggunaan APD menghasilkan p-value sebesar 0,051 yang artinya ada hubungan yang signifikan antara pengetahuan dengan kepatuhan penggunaan APD. Hasil analisis diperoleh juga nilai Odds Ratio (OR) sebesar 1,729 sehingga dapat dikatakan bahwa responden dengan pengetahuan baik memiliki peluang 1,729 kali lebih tinggi untuk patuh menggunakan APD dibandingkan dengan responden yang memiliki pengetahuan kurang.

Hasil analisis variabel sikap didapatkan persentase responden dengan sikap baik diperoleh sebesar 70,5\% patuh penggunaan APD, sedangkan pada responden dengan sikap kurang sebesar 67,4\% patuh penggunaan APD. Hasil uji chi-square sikap dengan kepatuhan penggunaan APD tidak menunjukan adanya hubungan signifikan dengan $p$-value 0,627 .

Pada variabel kenyamanan didapat sebesar 83,3\% responden dengan merasa nyaman menggunakan APD patuh penggunaan APD, sedangkan pada responden yang tidak merasa nyaman menggunakan APD didapatkan sebesar 68,7\% patuh penggunaan APD. Hasil uji chi-square kenyamanan dengan kepatuhan penggunaan APD tidak menunjukan adanya hubungan signifikan dengan $p$-value 0,356 .

Hasil analisis variabel ketersedian APD didapat sebesar 66,8\% responden dengan ada ketersediaan APD patuh penggunaan APD, sedangkan pada responden yang tidak tersedia APD didapatkan sebesar 76,2\% patuh penggunaan APD. Hasil uji chi-square ketersediaan dengan kepatuhan penggunaan APD tidak menunjukan adanya hubungan signifikan dengan $p$-value 0,132 .

Pada variabel rekan mahasiswa didapat sebesar 70,2\% responden dengan adanya dorongan rekan mahasiswa membuat membuat patuh penggunaan APD, sedangkan pada responden dengan tidak ada dorongan rekan mahasiswa didapatkan sebesar 46,2\% patuh penggunaan APD. Hasil uji chi-square dorongan rekan mahasiswa dengan kepatuhan penggunaan APD tidak menunjukan adanya hubungan signifikan dengan $p$-value 0,120 .

Pada variabel pengawasan didapat sebesar 70,0\% responden dengan pengawasan baik patuh penggunaan APD, sedangkan pada responden dengan pengawasan kurang didapatkan sebesar 66,7\% patuh penggunaan APD. Hasil uji chi-square pengawasan dengan kepatuhan penggunaan APD tidak menunjukan adanya hubungan signifikan dengan $p$-value 0,581 .

Pada variabel peraturan didapat sebesar $68,0 \%$ responden dengan adanya peraturan membuat patuh 
penggunaan APD, sedangkan pada responden tidaka ada peraturan didapatkan sebesar 89,5\% patuh penggunaan APD. Hasil uji chi-square peraturan dengan kepatuhan penggunaan APD menghasilkan pvalue sebesar 0,070 yang artinya ada hubungan yang signifikan antara peraturan dengan kepatuhan penggunaan APD. Hasil analisis diperoleh juga nilai Odds Ratio (OR) sebesar 0,250 sehingga dapat dikatakan bahwa responden dengan adanya peraturan memiliki peluang 0,250 kali lebih tinggi untuk patuh menggunakan APD dibandingkan dengan responden yang mengatakan tidak ada peraturan.

Hasil analisis variabel sanksi didapat sebesar 68,5\% responden yang mengatakan adanya sanksi patuh penggunaan APD, sedangkan pada responden yang tidak ada sanksi didapatkan sebesar $72,7 \%$ patuh penggunaan APD. Hasil uji chi-square sanksi dengan kepatuhan penggunaan APD tidak menunjukan adanya hubungan signifikan dengan $p$-value 0,632 .

\section{PEMBAHASAN}

Hasil penelitian variable pengetahuan ini sejalan penelitian Andri (2017) bahwa sebagian besar pekerja dengan pengetahuan (77,3\%). Hasil uji statistic mengggunakan chi-square diperoleh p-value 0,008 sehingga ada hubungan antara pengetahuan dengan kepatuhan penggunaan APD.

Hasil penelitian variable sikap ini sejalan dengan penelitian Johny (2000) yang mengatakan bahwa tidak ada perbedaan bermakna antara sikap dengan penggunaan APD dengan nilai $\mathrm{p}=0,336$, dan juga penelitian Aniek (2016) hasil penelitiannya menunjukan adanya hubungan yang signifikan antara sikap dengan kepatuhan memakai APD dengan chi-square hitung sebesar 4,968 ( $\mathrm{p}=0,026)$

Penelitian variable kenyamanan ini tidak sejalan dengan penelitian Cushman dan Rosenberg (1991) dalam Aniek (2016) yang membuktikan bahwa terdapat hubungan yang signifikan antara kenyamanan dengan kepatuhab penggunaan APD degan niali chi- square hitung sebesar 19,212 ( $p=0,000, p<0,005)$. Hubungan antara kedua variabel in bersifat lurus artinya semakin nyaman menggunakan APD maka semakin patuh untuk menggunakan APD.

Penelitian lain berbeda dengan hasil penelitian ini. Penelitian Aniek (2016) membuktikan adanya hubungan yang signifikan antara ketersediaan APD dengan kepatuhan memakai APD dengan nilai $\mathrm{p}=0,000$. Ketersediaan APD membuat pekerja patuh menggunakan APD.

Hasil penelitian ini sejalan dengan penelitian yang dilakukan oleh Nanang pada pekerja pengecoran logam PT. Sinar Semesta Batur yang menyatakan bahwa informan tidak berpengaruh terhadapperilaku rekan kerja yang menggunakan APD. Rekan kerja dapat juga mempengaruhi perilaku seseorang karena rekan kerja merupakan salah satu teman terdekat yang bisa menjadi contoh dalam berperilaku, baik contoh yang benar atau yang salah. Menurut teori Green menjelaskan bahwa faktor penguat dari luar yakni peer influence dari teman terdekat atau lingkungan sekitar dapat mempengaruhi seseorang. Hal ini sejalan dengan penelitian Ruhyandi (2008) yang mengatakan tidak terdapat hubungan yang bermakna $(p=0,255>0,05)$ antara pengawasan dengan perilaku kepatuhan penggunaan APD. Penelitian ini berbeda dengan penelitian Johny (2000) yang mengatakan pengawasan mempunyai hubungan signifikan terhadap penggunaan APD dengan nilai $\mathrm{p}=0,015$.pengawasan merupakan kegiatan rutin dalam bentuk observasi harian terhadap penggunaan APD yang dilakukan oleh pengawas. 


\section{KESIMPULAN DAN REKOMENDASI}

Hasil dari penelitian yang dilakukan adalah responden yang patuh menggunakan APD sebanyak 69,2\% dan responden tidak patuh mengggunakan APD sebanyak 30,8\%. Terdapat hubungan yang signifikan antara variabel pengetahuan $(O R=1,729)$, variabel rekan mahasiswa $(O R=2,743)$, variabel peraturan $(O R=0,250)$ dengan kepatuhan penggunaan APD. Variabel yang paling dominan yang berhubungan dengan kepatuhan penggunaan APD adalah hubungan rekan mahasiswa dengan $\mathrm{OR}=3,039$.

Saran yang diberikan adalah memberikan sanksi yang tegas terhadap mahasiswa yang tidak menggunakan APD secara lengkap, melakukan pengawasan yang ketat ketika mahasiswa melakukan kegiatan di laboratorium, membantu kelancaran ketersediaan APD sehingga mahasiswa mudah mendapatkan APD. Peneliti selanjutnya disarankan untuk meneliti variabel-variabel kepatuhan penggunaan APD lainnya, meneliti dengan teknik kualitatif. Peneliti lain juga dapat meneliti faktor lain yang berhubungan dengan kepatuhan penggunaan APD di tempat yang berbeda.

\section{REFERENSI}

1. Aniek. 2016. Faktor-Faktor yang Berhubungan dengan Kepatuhan Penggunaan APD Earplug dan sarung tangan pada Pekerja Unit Perbaikan di PT KAI VI Yogyakarta Dipo Solo Balapan. FKM. Universitas Muhammadiyah Surakarta.

2. Universitas MH Thamrin. 2016. Buku IIIB. Borag Unit Pengelola Program studi

3. Universtas MH Thamrin. 2016. Borang Akreditasi Program Studi.

4. Yane.2011. hubungan tingkat pengetahuan dan sikap dengan perilaku penggunaan alat pelindung diri pada mahasiswa Prodi DIII Analis Kesehatan STIKes BTH Tasikmalaya.jurnal kesehatan Bakti Tunas Husada. Volume 17 Nomor 2 Agustus 2017 